\title{
Refractive cylinder outcomes after calculating toric intraocular lens cylinder power using total corneal refractive power
}

This article was published in the following Dove Press journal:

Clinical Ophthalmology

19 August 2015

Number of times this article has been viewed

\author{
James A Davison' \\ Richard Potvin ${ }^{2}$ \\ 'Wolfe Eye Clinic, Marshalltown, IA, \\ USA; ${ }^{2}$ Science in Vision, Akron, NY, \\ USA
}

Correspondence: Richard Potvin Science in Vision, 6197 Dye Road, Akron, NY I400I, USA

$\mathrm{Tel}+\mathrm{I} 4076976008$

Fax + I 7164425110

Email rick@scienceinvision.com
Purpose: To determine whether the total corneal refractive power (TCRP) value, which is based on measurement of both anterior and posterior corneal astigmatism, is effective for toric intraocular lens (IOL) calculation with AcrySof ${ }^{\circledR}$ Toric IOLs.

Patients and methods: A consecutive series of cataract surgery cases with AcrySof toric IOL implantation was studied retrospectively. The IOLMaster ${ }^{\mathbb{R}}$ was used for calculation of IOL sphere, the Pentacam ${ }^{\circledR}$ TCRP $3.0 \mathrm{~mm}$ apex/ring value was used as the keratometry input to the AcrySof Toric IOL Calculator and the VERIONTM Digital Marker for surgical orientation. The keratometry readings from the VERION reference unit were recorded but not used in the actual calculation. Vector differences between expected and actual residual refractive cylinder were calculated and compared to simulated vector errors using the collected VERION keratometry data.

Results: In total, 83 eyes of 56 patients were analyzed. Residual refractive cylinder was 0.25 $\mathrm{D}$ or lower in $58 \%$ of eyes and $0.5 \mathrm{D}$ or lower in $80 \%$ of eyes. The TCRP-based calculation resulted in a statistically significantly lower vector error $(P<0.01)$ and significantly more eyes with a vector error $\leq 0.5 \mathrm{D}$ relative to the VERION-based calculation $(P=0.02)$. The TCRP and VERION keratometry readings suggested a different IOL toric power in 53/83 eyes. In these 53 eyes the TCRP vector error was lower in 28 cases, the VERION error was lower in five cases, and the error was equal in 20 cases. When the anterior cornea had with-the-rule astigmatism, the VERION was more likely to suggest a higher toric power and when the anterior cornea had against-the-rule astigmatism, the VERION was less likely to suggest a higher toric power.

Conclusion: Using the TCRP keratometry measurement in the AcrySof toric calculator may improve overall postoperative refractive results. Consideration of measured posterior corneal astigmatism, rather than a population-averaged value, appears advantageous.

Keywords: toric IOL, posterior corneal astigmatism, astigmatism, keratometry, biometry, TCRP

\section{Introduction}

Approximately three out of four patients presenting for routine cataract surgery are likely to have preoperative corneal astigmatism of $0.75 \mathrm{D}$ or more. ${ }^{1}$ These patients are potential candidates for toric intraocular lens (IOL) implantation as toric IOLs have been shown to be one of the most effective and predictable ways to reduce residual refractive cylinder. ${ }^{2-4}$ Despite the demonstrated effectiveness of toric IOLs, a certain portion of patients still have clinically significant residual refractive cylinder postoperatively. The initial study of AcrySof ${ }^{\circledR}$ Toric IOL (Alcon, Fort Worth, TX, USA) performance showed that out of 256 patients implanted with toric IOLs, $12 \%$ had $>1.0$ $\mathrm{D}$ of residual astigmatism postoperatively. ${ }^{5}$ 
There are a number of reasons which might explain why patients may have residual astigmatism after uneventful cataract surgery using toric IOLs. These include preoperative factors such as dry eye, which might increase variability in corneal astigmatism measurement, and postoperative factors such as final toric IOL orientation, variability in surgically induced astigmatism, and subjective variability in postoperative refraction performance. However one recent study has suggested that posterior corneal astigmatism might have the greatest impact on astigmatism error after uneventful cataract surgery with toric IOLs. ${ }^{6}$

The existence of significant posterior corneal astigmatism in some eyes, and its effect on corneal power, has been previously demonstrated. ${ }^{7}$ An early study using a rotating Scheimpflug imaging system (Oculus Pentacam ${ }^{\circledR}$ HR, OCULUS Optikgeräte GmbH, Wetzlar, Germany) showed that in eyes with $\geq 1.0 \mathrm{D}$ of anterior corneal astigmatism, $10.3 \%$ had total corneal astigmatism (anterior plus posterior) which differed from anterior astigmatism by more than $>0.5 \mathrm{D}$ in magnitude or more than 10 degrees in orientation. ${ }^{8}$ One of the largest studies $(3,818$ eyes) reported was by Tonn et $\mathrm{al}^{9}$ using the same system. They found that the average amount of posterior corneal astigmatism was $-0.33 \pm 0.18 \mathrm{D}$ (range 0.00 to $-1.35 \mathrm{D}$ ) and that more than $15 \%$ of eyes studied had $>0.50 \mathrm{D}$ of posterior corneal astigmatism. These results were similar to those reported by Miyake et $\mathrm{al}^{10}$ using the same tomographer, and Koch et al who used a different dualScheimpflug analyzer. ${ }^{11}$ All three studies found that most eyes (87\%-91\%) have against-the-rule (ATR) posterior corneal astigmatism. As such, not measuring the posterior corneal astigmatism may result in implanting a higher-thanneeded toric IOL power in corneas having anterior with-therule (WTR) astigmatism and a lower-than-needed toric IOL power in corneas having anterior ATR astigmatism. ${ }^{12}$ This was especially evident in eyes receiving toric IOL powers below 2.0 D, where the effects of posterior corneal astigmatism have a relatively higher influence on total corneal astigmatism. ${ }^{13}$

Several studies have suggested empirically derived nomograms to compensate for the effects of posterior corneal astigmatism. ${ }^{12,13}$ However, any nomogram adjustments based on sample averages of residual refractive cylinder may not be effective in all cases because of the variability in the contribution of posterior corneal astigmatism between individual patients. ${ }^{10}$ As such, the best solution is to make an accurate measurement of both anterior and posterior corneal astigmatism in each patient and use the total corneal astigmatism value to calculate the required toric IOL power.
The most commonly used keratometry devices do not measure posterior corneal power. ${ }^{12}$ A rotating Scheimpflug system is one device which is capable of measuring both the anterior and posterior corneal curvature. In the case of the Pentacam's ray-tracing technology, corneal power of the anterior surface and posterior surface can be determined at a number of selected distances from either the pupillary center or corneal apex using a ring (perimeter) or zone (the area within a given radius), with the result termed the total corneal refractive power (TCRP). ${ }^{1}$ This technology has been found to provide valid and reliable measurements for the purposes of toric IOL planning. ${ }^{6,10}$

The purpose of the study reported here was to investigate whether the TCRP value would provide a valid and reliable measurement of corneal astigmatism for toric IOL calculation using AcrySof Toric IOLs.

\section{Methods}

Institutional review board (Wolfe Eye Clinic Internal Institutional Review Board) approval for a patient record review was requested and obtained. Patient records were reviewed to identify a series of consecutive cases of toric IOL implantation operated from August 2013 to June 2014 by a single surgeon (JAD). The cases had the following characteristics: regular anterior corneal astigmatism, no pathology which might preclude accurate manifest refraction or recovery from surgery, implantation with AcrySof ${ }^{\circledR}$ IQ Toric hydrophobic singlepiece acrylic lenses, IOL spherical power based on axial length and keratometry from the IOLMaster ${ }^{\circledR}$ (Carl Zeiss Meditec, Jena, Germany), and TCRP from the Pentacam at the $3.0 \mathrm{~mm}$ apex/ring setting on the power distribution map for keratometry entry into the Alcon AcrySof Toric IOL Calculator (http://www.acrysoftoriccalculator.com/). Keratometry data from the reference unit component of the VERIONTM Image Guided System (Alcon) was recorded and used to create a later theoretical toric IOL calculation but those measurements and calculations were not used for actual surgery. Surgically induced astigmatism for the purposes of toric IOL planning was $0.25 \mathrm{D}$ at 190 degrees in the right eye and 17 degrees in the left, calculated based on the surgeon's historical results.

Cataract surgery was performed in standard contemporary fashion; that is, topical-intracameral anesthesia, $2.4 \mathrm{~mm}$ bi-beveled keratome near-clear self-sealing temporal incisions, and "divide-and conquer" phacoemulsification with an anterior capsule overlap target of $0.7 \mathrm{~mm}$ over the peripheral optic for 360 degrees. The Digital Marker component of the VERION Image Guided System was used to orient the toric IOLs at the time of surgery (Figure 1). At the last postoperative visit the manifest refraction and the orientation of the 


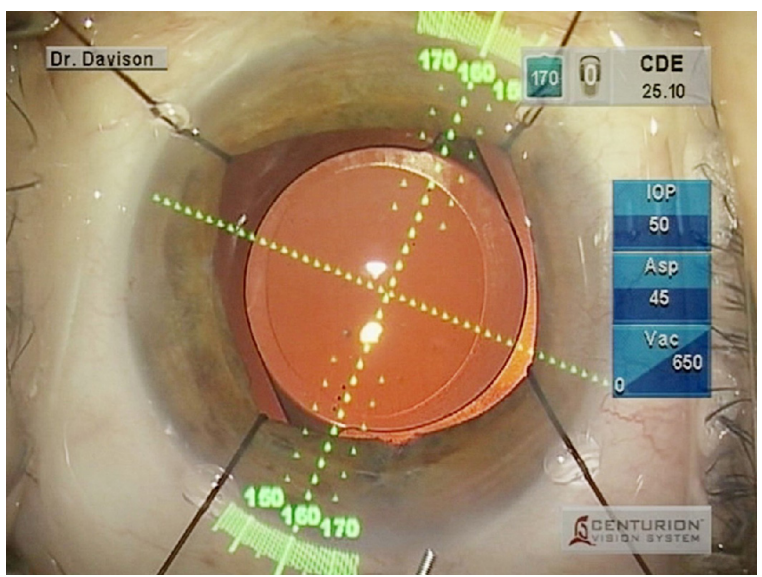

Figure I The VERION ${ }^{T M}$ Image Guided System microscope overlay for toric intraocular lens alignment.

Abbreviations: Asp, aspiration; CDE, cumulative distributed energy; Vac, vacuum.

IOL were recorded, along with postoperative keratometry by IOLMaster.

Data collection involved extracting preoperative keratometry, biometry, VERION keratometry readings, and TCRP measurements along with postoperative keratometry, manifest refraction, and the orientation of the IOL.

For the purposes of the analysis, any eye with an IOL judged to be oriented more than 10 degrees from intended was eliminated from the final dataset. This was done to reduce the potential confounding effects of postoperative misalignment, as the interest in the current dataset was limited to the effects of the toric IOL calculation. Because of limitations in the range of the toric IOL used, eyes with $>4.25 \mathrm{D}$ of anterior corneal astigmatism (measured by the IOLMaster) were also excluded.

Analysis included a summary of the postoperative refractive status of all eyes as determined by manifest refraction. The vector error in the actual (TCRP-based) toric IOL result was calculated by comparing actual achieved versus expected residual refractive cylinder provided by the toric IOL calculator. Figure 2A illustrates the vector components of such a calculation. In addition to the actual TCRP versus expected calculation, a simulation of results with a second calculation was performed using a technique described by Hill et al. ${ }^{14}$ To achieve this comparison, the actual IOL implanted using the TCRP data was mathematically "removed" and the IOL suggested by the AcrySof toric calculator using the VERION data was mathematically "implanted". Figure 2B illustrates the vector effect of this "simulated replacement". When that replacement was completed, a new residual refractive error and expected residual astigmatism from the AcrySof toric calculator using VERION data were derived and then used to calculate a new vector error of simulated actual achieved versus expected as shown in Figure 2C. The method of backcalculation of the toric IOL power was based on the method of Fam and Lim. ${ }^{15}$ The vector errors from the actual versus VERION-based calculations were compared with cylinder orientation as a categorical variable (WTR, oblique [OBL],
A Calculating vector error

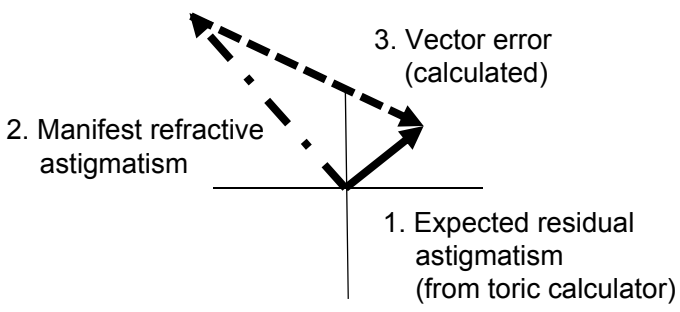

\section{B Simulated lens replacement}

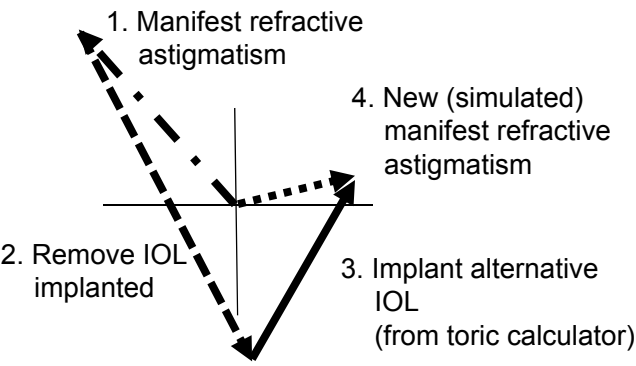

\section{Simulated vector error}

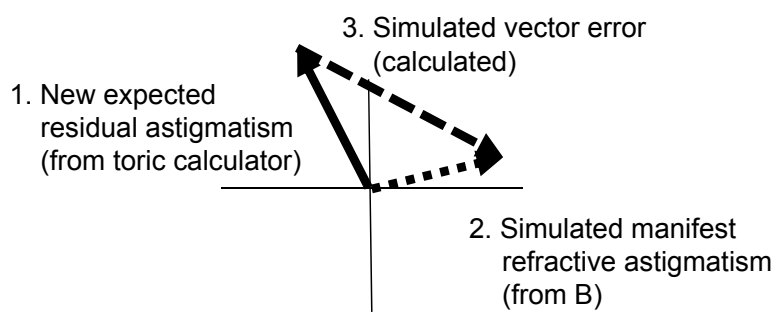

Figure 2 Calculating vector errors.

Notes: Calculating vector errors with the actual manifest refractive astigmatism (A), or simulated manifest refractive astigmatism (C), the latter based on the simulated astigmatism derived in (B). The numerals indicate the steps in the calculation.

Abbreviation: IOL, intraocular lens. 
ATR); a steep corneal meridian within 30 degrees of vertical was considered WTR, a steep corneal meridian within 30 degrees of horizontal was considered ATR, and the 30 degrees in between was considered OBL.

Data from the identified patient charts were recorded in an Excel spreadsheet; this spreadsheet was imported into an Access database for data checking, collation, and preliminary analysis (both Microsoft Corporation, Redmond, WA, USA). Statistical analyses were performed using the STATISTICA data analysis software system (v 12; StatSoft, Inc, Tulsa, OK, USA). Statistical testing was performed using analysis of variance for continuous variables and appropriate nonparametric testing (eg, Fisher's exact test) for categorical variables. Statistical significance was set at level alpha $=0.05$.

\section{Results}

Chart review identified 83 eyes of 56 patients which met the inclusion criteria, with an almost equal number of right and left eyes (42 and 41, respectively). Table 1 summarizes the general characteristics of the studied sample. Results suggest that the study population had a good representative range of ages, axial lengths, and keratometry values. The mean time to manifest refraction was 55 days postoperative. A test for between-eye correlation indicated that correlation bias was low, so all data were pooled for analysis. ${ }^{16}$

Spherical IOL power was determined using the lower of the results from the Haigis and SRK/T formulas. The mean spherical equivalent refractive error (after adjusting for any monovision targets) was $-0.06 \pm 0.36 \mathrm{D}$, with a range of from -1.25 to +0.75 D. Two-thirds of eyes $(67 \%, 56 / 83)$ had a spherical equivalent refraction within $0.25 \mathrm{D}$ of intended, while $94 \%$ had a spherical equivalent refraction within $0.5 \mathrm{D}$ of intended.

The vector difference between the anterior corneal astigmatism, as measured by the IOLMaster (a standard for pre-surgical biometry), and the measured TCRP was statistically and clinically significant $(0.50 \pm 0.33 \mathrm{D}, P<0.01)$. Measured TCRP astigmatism was generally higher than anterior corneal astigmatism in eyes with ATR and OBL anterior corneal astigmatism and lower in eyes with WTR anterior corneal astigmatism.

Figure 3 shows the distribution of postoperative refractive cylinder. More than half the eyes $(58 \%, 48 / 83)$ had a residual cylinder of $0.25 \mathrm{D}$ or lower, $80 \%(66 / 83)$ had $0.5 \mathrm{D}$ or lower, and no eye had a residual refractive cylinder $>1.25 \mathrm{D}$ after surgery. While some eyes were evaluated in the early postoperative period $(7 \%, 6 / 83$, with results 9-14 days postoperative), there was no statistically significant difference between the postoperative refractive cylinder measured in eyes with a follow-up visit $<14$ days and those with a longer follow-up $(P=0.48)$.

Figure 4 shows the vector error for both the actual and the simulated VERION toric IOL calculation; the vector error calculations are described in the "Methods" section. Table 2 summarizes the findings with regard to the vector error. A repeated-measures analysis of variance showed a statistically significantly lower mean vector error in the TCRP calculation $(P<0.01)$. There were 56 eyes in the TCRP group and 40 eyes in the VERION group with a vector error $\leq 0.5 \mathrm{D}$. This difference was also statistically significant $(P=0.02)$.

The recommended IOL was also compared between calculation methods. Of interest was the orientation of the anterior corneal cylinder and the relative difference in IOL power selection. Table 3 shows the breakdown between the methods. In almost two out of three cases $(64 \%, 53 / 83)$ the toric IOL cylinder power was different between the two methods. Where there was a difference, the likelihood was that the cylinder power calculated with the VERION system was higher when the anterior astigmatism was WTR and lower when the anterior astigmatism was ATR, but this was not true in all cases.

For WTR astigmatism, the calculated cylinder power with the VERION data was higher than for the TCRP data in $61 \%$ of cases (30/49). For ATR astigmatism the majority of lens cylinder selections was equal but when there was a difference the calculated cylinder power with the TCRP data was higher more often. With OBL astigmatism, there

Table I Characteristics of the dataset

\begin{tabular}{|c|c|c|c|c|}
\hline Characteristic & Mean & Standard deviation & Minimum & Maximum \\
\hline Age (years) & 67 & 8.50 & 45.00 & 86.000 \\
\hline Preoperative spherical equivalent refraction (D) & -2.94 & 3.60 & -13.25 & 4.125 \\
\hline Preoperative manifest astigmatism (D) & 1.38 & 0.95 & 0.00 & 4.250 \\
\hline Axial length $(\mathrm{mm})$ & 24.72 & 1.37 & 22.09 & 28.310 \\
\hline Average keratometry (VERION ${ }^{\mathrm{TM}}$ ) (D) & 43.99 & 1.47 & 41.08 & 46.880 \\
\hline Average keratometry (TCRP) (D) & 43.31 & $1.4 \mid$ & 40.50 & 45.850 \\
\hline Corneal astigmatism (VERION) (D) & 1.50 & 0.70 & 0.20 & 3.450 \\
\hline Corneal astigmatism (TCRP) (D) & 1.56 & 0.69 & 0.60 & 3.600 \\
\hline Days postoperative & 56 & 32.00 & 9.00 & 151.000 \\
\hline
\end{tabular}

Abbreviation: TCRP, total corneal refractive power. 


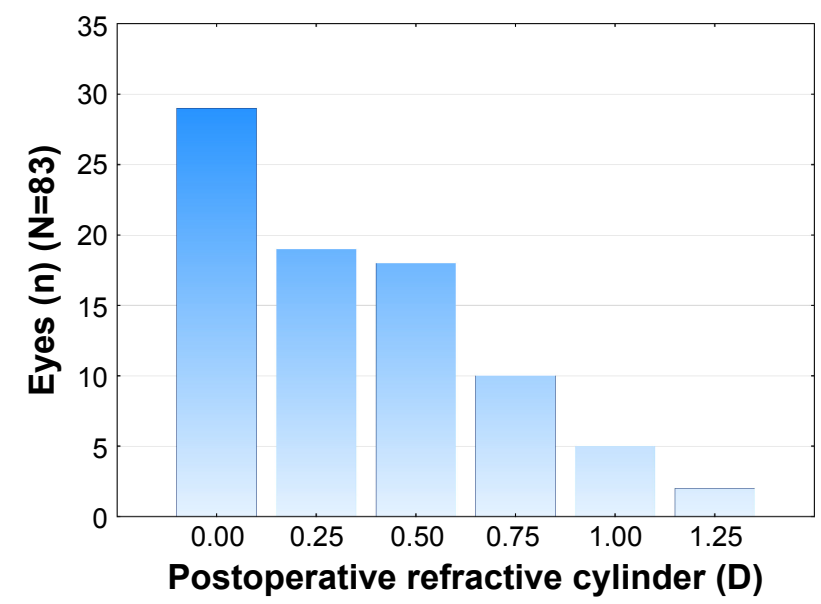

Figure 3 Postoperative refractive cylinder.

was an equal number of cases where one method suggested a higher cylinder power than the other. Vector errors within $0.25 \mathrm{D}$ of each other were considered "equal". As can be seen in columns 3 and 5 of Table 3, when the lens selection was different between the two calculation methods (ie, in 53 of the 83 cases), the TCRP vector error was lower in 28 cases, the vector errors were equal in another 20 cases, and in only five cases was the VERION vector error lower.

\section{Discussion}

Consideration of each individual's posterior cornea for toric power calculation can have a significant positive effect on the success of toric IOL implantation. In the case series analyzed here, the TCRP was used for toric IOL calculation. Results showed $80 \%$ of eyes with $0.5 \mathrm{D}$ or less of refractive astigmatism postoperatively. This compares favorably to two of the largest studies of clinical outcomes with the AcrySof Toric IOL. Holland et al reported $53 \%$ of eyes (128/242) with $0.5 \mathrm{D}$ or less of refractive cylinder postoperatively, ${ }^{5}$ while Ahmed et al reported $71 \%(116 / 174)$ with the same result. ${ }^{4}$ Both of these studies included use of the AcrySof Toric Calculator, but used only anterior corneal astigmatism for the calculation of IOL cylinder power.

It is important to note that because standard IOL calculation formula for sphere power are designed for use with the performance and assumptions of anterior keratometry, the TCRP data

Table 2 Vector errors (difference from expected)

\begin{tabular}{llll}
\hline Vector difference & $\begin{array}{l}\text { TCRP } \\
\text { (actual) }\end{array}$ & $\begin{array}{l}\text { VERION } \\
\text { (simulated) }\end{array}$ & P-value \\
\hline Mean (D) & 0.46 & 0.61 & $<0.01$ \\
Standard deviation (D) & 0.31 & 0.41 & \\
Eyes within (n) (N=83) & & & \\
0.5 D & 56 & 40 & 0.02 \\
I.0 D & 76 & 72 & \\
\hline
\end{tabular}

Abbreviations: TCRP, total corneal refractive power.

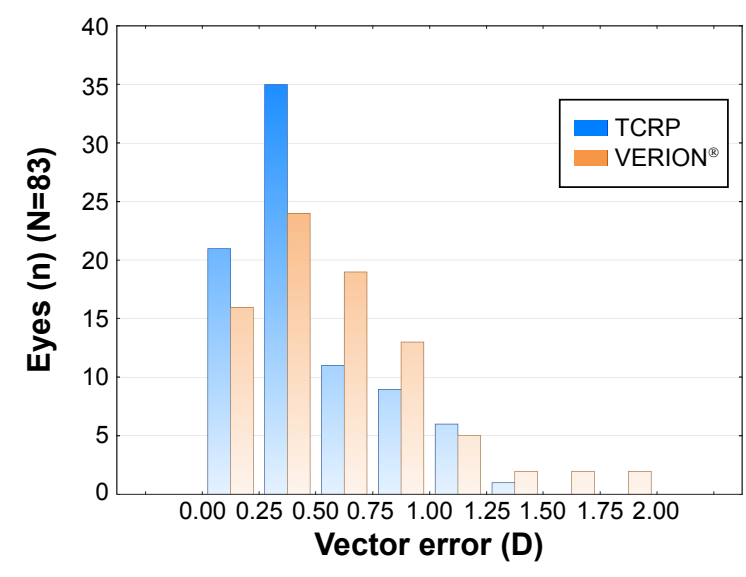

Figure 4 Vector error in astigmatism calculation.

Abbreviation: TCRP, total corneal refractive power.

cannot be used for spherical power calculation. As is evident in Table 1, the difference in average keratometry between the TCRP measurement and the VERION measurement (which includes only anterior corneal power) was $>0.5 \mathrm{D}$. This is a larger difference than that noted by Tonn et al who compared the TCRP in the $3 \mathrm{~mm}$ zone (as opposed to the $3 \mathrm{~mm}$ ring value used in our study) with the simulated keratometry (Sim-K; which includes only anterior corneal power) measurement from the rotating Scheimpflug device. ${ }^{9}$ The results of that study showed that the vector difference between TCRP and Sim-K was 0.18 \pm 0.19 D, though 9\% of eyes had a mean vector difference of more than $0.50 \mathrm{D} .{ }^{9}$ The differences may in part be due to using the VERION versus the Sim-K measure from the Pentacam and the TCRP ring versus zone measurement. Table 1 also only includes magnitude differences; we did not make a vector difference calculation.

The mean error vector, the difference between the expected result and the actual result (or simulated result for the VERION data), was significantly lower when the TCRP data were used for cylinder power calculation. A significantly higher percentage of patients had $\leq 0.5 \mathrm{D}$ of vector error when using the TCRP data as opposed to the simulated VERION data. This is a "real" error, independent of the toric calculator used, because the error calculation compensates for the residual astigmatism predicted by the toric

Table 3 Anterior corneal astigmatism orientation and toric intraocular lens cylinder power recommendation by device

\begin{tabular}{lllll}
\hline Orientation & $\begin{array}{l}\text { Eyes } \\
(\mathbf{n})\end{array}$ & $\begin{array}{l}\text { TCRP } \\
\text { higher }\end{array}$ & Equal & $\begin{array}{l}\text { VERION } \\
\text { higher }\end{array}$ \\
\hline With-the-rule & 49 & $4(3 \mathrm{~T}, \mathrm{IE})$ & 15 & $30(\mathrm{I4T}, \mathrm{I2E}, 4 \mathrm{~V})$ \\
Oblique & 15 & $6(4 \mathrm{~T}, 2 \mathrm{E})$ & 4 & $5(2 \mathrm{~T}, 3 \mathrm{E})$ \\
Against-the-rule & 19 & $6(3 \mathrm{~T}, 2 \mathrm{E}, \mathrm{IV})$ & $\mathrm{II}$ & $2(2 \mathrm{~T})$ \\
\hline
\end{tabular}

Notes: Numbers following in brackets show the breakdown of vector errors. Letters following the numbers indicate: T, TCRP vector error lower; E, vector errors equal; $\checkmark$, VERION vector error lower.

Abbreviation: TCRP, total corneal refractive power. 
calculator. A previous study also found that measurement of the total corneal astigmatism, using the same tomographer we used in our study, reduced the residual refractive astigmatism; this is in agreement with the results shown here. ${ }^{6}$

In contrast, a study by Zhang et al which also used the AcrySof IQ Toric IOL and AcrySof Toric IOL Calculator, did not find a statistically significant difference in the mean error between the automated keratometer and total corneal power as measured using a different Scheimpflug tomographer. ${ }^{17}$ Koch et al used the same tomographer as Zhang et al and noted that its total corneal power appeared to underestimate posterior corneal astigmatism in eyes with WTR astigmatism, which could explain some of the differences. ${ }^{12}$

Overall, the results here are consistent with the expectations from previous research by Tonn et al, Koch et al, and Goggin et al. ${ }^{9,11,13}$ It appears that the posterior cornea has a relatively consistent orientation of astigmatism, independent of the orientation of the astigmatism on the anterior cornea. This explains the propensity for the VERION calculation to indicate a higher cylinder power when anterior corneal astigmatism was WTR and a lower cylinder power (ie, TCRP higher) when the anterior corneal astigmatism was ATR, as evidenced by the top right and bottom left cells in Table 3 (text in bold). Looking at the associated vector errors in those cells, the VERION calculation was significantly less accurate in these instances, the TCRP vector error was lower in 17 of 36 of these cases, the vector errors were equal in another 14 cases, and the VERION vector error was lower in only five cases.

The results here suggest that TCRP may help decrease the systematic error of overcorrecting WTR astigmatism and undercorrecting ATR astigmatism that is often reported when the posterior corneal astigmatism is not measured. This is in agreement with another study reporting that the total corneal power measured with a different Scheimpflug tomographer prevented this systematic error when compared with an automated keratometer that only measured the anterior corneal curvature. ${ }^{17}$

The distribution of vector errors noted is important because the results were not universal - not all higher cylinder calculations with the VERION data were incorrect, for instance. As a result, it is very unlikely that a global correction factor based on average posterior corneal astigmatism, such as those suggested by Koch et al and Goggin et al ${ }^{12,13}$ would be as accurate as patient-specific measures of posterior corneal astigmatism. Savini et al examined a series of eyes with moderate to high amounts of anterior corneal astigmatism. ${ }^{18}$ They reported a high degree of correlation between WTR anterior astigmatism and posterior corneal astigmatism, but no such correlation between ATR astigmatism and posterior corneal astigmatism; it is apparent that individual variability of posterior corneal astigmatism is high.

One additional note is that the AcrySof Toric Calculator is designed to suggest a toric cylinder power that never overcorrects the measured corneal astigmatism, regardless of the source of the measurement (TCRP or anterior only). When only an anterior corneal astigmatism measurement is used, this can be beneficial in WTR corneas where the problem is likely to be overcorrection, but detrimental in ATR corneas, where cylinder is generally undercorrected. ${ }^{13}$ This would be important to consider when evaluating the results here. If not considering the effects of the posterior cornea, one would expect a general underestimate of the toric IOL cylinder power from the AcrySof Toric Calculator, regardless of the orientation of the steep meridian of the anterior cornea. With consideration of the posterior corneal astigmatism, the underestimate would be smaller, but it would still be helpful for surgeons to look at the expected residual refractive astigmatism, reported on the calculator printout, to decide if it might be better to use the next higher cylinder power and 'flip' the axis. For instance, if the expected residual refractive astigmatism is $0.45 \mathrm{D}$ at 90 degrees, the next higher cylinder power would be expected to yield a residual of $0.05 \mathrm{D}$ at 0 degrees; the latter might be preferred.

\section{Limitations}

A limitation of the current study is its retrospective nature. The follow-up period varied for different patients, and refractive cylinder may be variable in the early postoperative period. The limited number of eyes seen between 9 days (the minimum follow-up) and 2 weeks postoperatively, and the lack of a statistically significant difference in postoperative cylinder between eyes with early and later follow-up, suggests the overall results reported here were not materially affected by this.

Another limitation of the study is that only the $3 \mathrm{~mm}$ apex/zone data from the Scheimpflug system were used for analysis, as these have been demonstrated to provide low mean absolute measurement errors. ${ }^{19}$ A sensitivity analysis of other possible measures might be helpful in determining if the $3 \mathrm{~mm}$ apex/zone value is the best one to use, but such analysis was beyond the scope of the current study.

The data were limited to eyes with a lens orientation within 10 degrees of intended. This was to reduce the variability of the postoperative results that were not related to the IOL calculation, which would confound the analysis. With accurate planning and orientation data, a back-calculation of the effect of the toric IOL at the ideal orientation is possible, but was not performed in this study. 
Another limitation of the current study is that we did not consider the effect of TCRP on spherical power. To use TCRP for spherical IOL power would require an optimization of any IOL power calculation formula specifically for TCRP. While we did not do this, Savini et al found that anywhere between $73 \%$ and $80 \%$ (based on the formula used) was within $\pm 0.50 \mathrm{D}$ of the target refraction. ${ }^{19}$ It is important to reiterate that they optimized their IOL calculation formula for TCRP before using TCRP in the formula; failure to do so would have significantly (and negatively) affected outcomes.

\section{Conclusion}

The combination of the IOLMaster for sphere and the Pentacam's TCRP keratometry values incorporated into the AcrySof Toric IOL Calculator appear to provide good overall postoperative refractive results. Consideration of measured posterior corneal astigmatism on a per case basis, rather than an estimated population-averaged value, appears to provide good results to individual patients.

\section{Acknowledgment}

Sarah Makari, OD, a consultant to Science in Vision, received compensation for assisting in the writing and preparation of this paper.

\section{Disclosure}

James A Davison, is a consultant for Alcon. Richard Potvin, is a consultant to Alcon, Oculus, and Haag-Streit. The authors report no other conflicts of interest in this work.

\section{References}

1. Khan MI, Muhtaseb M. Prevalence of corneal astigmatism in patients having routine cataract surgery at a teaching hospital in the United Kingdom. J Cataract Refract Surg. 2011;37(10):1751-1755.

2. Ernest P, Potvin R. Effects of preoperative corneal astigmatism orientation on results with a low-cylinder-power toric intraocular lens. J Cataract Refract Surg. 2011;37(4):727-732.

3. Hirnschall N, Gangwani V, Crnej A, Koshy J, Maurino V, Findl O. Correction of moderate corneal astigmatism during cataract surgery: toric intraocular lens versus peripheral corneal relaxing incisions. J Cataract Refract Surg. 2014;40(3):354-361.
4. Ahmed II, Rocha G, Slomovic AR, et al; Canadian Toric Study Group. The AcrySof Toric intraocular lens in subjects with cataracts and corneal astigmatism: a randomized, subject-masked, parallel-group, 1-year study. J Cataract Refract Surg. 2010;36(4):609-616.

5. Holland E, Lane S, Horn JD, Ernest P, Arleo R, Miller KM. The AcrySof Toric intraocular lens in subjects with cataracts and corneal astigmatism: a randomized, subject-masked, parallel-group, 1-year study. Ophthalmology. 2010;117(11):2104-2111.

6. Savini G, Næser K. An analysis of the factors influencing the residual refractive astigmatism after cataract surgery with toric intraocular lenses. Invest Ophthalmol Vis Sci. 2015;56(2):827-835.

7. Oshika T, Tomidokoro A, Tsuji H. Regular and irregular refractive powers of the front and back surfaces of the cornea. Exp Eye Res. 1998;67(4):443-447.

8. Ho JD, Tsai CY, Liou SW. Accuracy of corneal astigmatism estimation by neglecting the posterior corneal surface measurement. Am J Ophthalmol. 2009;147(5):788-795.

9. Tonn B, Klaproth OK, Kohnen T. Anterior surface-based keratometry compared with Scheimpflug tomography-based total corneal astigmatism. Invest Ophthalmol Vis Sci. 2014;56(1):291-298.

10. Miyake T, Shimizu K, Kamiya K. Distribution of posterior corneal astigmatism according to axis orientation of anterior corneal astigmatism. PLoS One. 2015;10(1):e0117194.

11. Koch DD, Ali SF, Weikert MP, Shirayama M, Jenkins R, Wang L. Contribution of posterior corneal astigmatism to total corneal astigmatism. $J$ Cataract Refract Surg. 2012;38(12):2080-2087.

12. Koch DD, Jenkins RB, Weikert MP, Yeu E, Wang L. Correcting astigmatism with toric intraocular lenses: effect of posterior corneal astigmatism. J Cataract Refract Surg. 2013;39(12):1803-1809.

13. Goggin M, Zamora-Alejo K, Esterman A, van Zyl L. Adjustment of anterior corneal astigmatism values to incorporate the likely effect of posterior corneal curvature for toric intraocular lens calculation. $J$ Refract Surg. 2015;31(2):98-102.

14. Hill W, Osher R, Cooke D, et al. Simulation of toric intraocular lens results: manual keratometry versus dual-zone automated keratometry from an integrated biometer. J Cataract Refract Surg. 2011;37(12):2181-2187.

15. Fam HB, Lim KL. Meridional analysis for calculating the expected spherocylindrical refraction in eyes with toric intraocular lenses. J Cataract Refract Surg. 2007;33(12):2072-2076.

16. Murdoch IE, Morris SS, Cousens SN. People and eyes: statistical approaches in ophthalmology. Br J Ophthalmol. 1998;82(8): 971-973.

17. Zhang L, Sy ME, Mai H, Yu F, Hamilton DR. Effect of posterior corneal astigmatism on refractive outcomes after toric intraocular lens implantation. J Cataract Refract Surg. 2015;41(1):84-89.

18. Savini G, Versaci F, Vestri G, Ducoli P, Næser K. Influence of posterior corneal astigmatism on total corneal astigmatism in eyes with moderate to high astigmatism. J Cataract Refract Surg. 2014; 40(10):1645-1653.

19. Savini G, Barboni P, Carbonelli M, Hoffer KJ. Comparison of methods to measure corneal power for intraocular lens power calculation using a rotating Scheimpflug camera. J Cataract Refract Surg. 2013;39(4):598-604.
Clinical Ophthalmology

\section{Publish your work in this journal}

Clinical Ophthalmology is an international, peer-reviewed journal covering all subspecialties within ophthalmology. Key topics include: Optometry; Visual science; Pharmacology and drug therapy in eye diseases; Basic Sciences; Primary and Secondary eye care; Patient Safety and Quality of Care Improvements. This journal is indexed on Submit your manuscript here: http://www.dovepress.com/clinical-ophthalmology-journal

\section{Dovepress}

PubMed Central and CAS, and is the official journal of The Society of Clinical Ophthalmology (SCO). The manuscript management system is completely online and includes a very quick and fair peer-review system, which is all easy to use. Visit http://www.dovepress.com/ testimonials.php to read real quotes from published authors. 